\title{
Öğrencilerin Sigara Kullanımını Etkileyen Faktörlerin Belirlenmesi: Ondokuz Mayıs Üniversitesi Örneği, Samsun
}

\author{
Osman KILIÇ ${ }^{*}$, Uğur BAŞER ${ }^{1}$, Hasan Samet ABACI², Gamze AYDIN ERYILMAZ ${ }^{3}$ \\ ${ }^{\prime}$ Ondokuz Mayls Üniversitesi, Ziraat Fakültesi, Tarım Ekonomisi Bölümü, Samsun, TÜRKIYYE \\ ${ }^{2}$ Ondokuz Mayıs Üniversitesi, Ziraat Fakültesi, Zootekni Bölümü, Samsun, TÜRKIYYE \\ ${ }^{3}$ Ondokuz Mayls Üniversitesi, Samsun Meslek Yüksekokulu, Park ve Bahçe Bitkileri Bölümü, Samsun, TÜRKIYYE
}

\begin{tabular}{l}
\hline \multicolumn{1}{c}{ Geliş Tarihi/Received: $30.07 .2018 \quad$ Kabul Tarihi/Accepted: 21.10 .2018} \\
\hline ORCID ID (Yazar sirasma göre / by author order) \\
(D) orcid.org/0000-0002-0129-4034 (D)orcid.org/0000-0003-4961-2764 (D)orcid.org/0000-0002-1341-4056 (D)orcid.org/0000-0002-4440-8687 \\
"Sorumlu Yazar/Corresponding Author: okilic@omu.edu.tr
\end{tabular}

Öz: Araştırmanın amacı, Ondokuz Mayı Üniversitesi öğrencilerinin sigara kullanımını etkileyen faktörleri belirlemektir. Araştırma verileri, 384 öğrenciyle yapılan anketlerden oluşmaktadır. Sigara kullanan ve kullanmayan öğrenciler arasındaki farklılığın belirlenmesinde ki-kare testi, grup ortalamalarının karșılaștırılmasında t testi kullanılmıștır. Öğrencilerin sigara kullanımını etkileyen faktörler ise binary lojistik regresyon analiziyle belirlenmiş̧ir. Araştırma sonuçları, erkek öğrencilerin kızlara oranla daha fazla sigara kullandıklarını göstermektedir. Öğrencilerin sigara kullanımı, üniversiteye başladıktan sonra özellikle ikinci ve üçüncü sınıfta artmaktadır. Bununla birlikte ebeveynlerin eğitim durumu ile sigara içmelerinin, öğrencinin sigara kullanımını etkilediği tespit edilmiștir. Model sonuçlarına göre sigara kullanımını etkileyen en önemli faktörler; öğrencinin ikamet ettiği yerde sigara içilmesi, annenin sigara içmesi, öğrencinin cinsiyeti ve yaşı olarak belirlenmiștir. Öğrencilerde sigara kullanımının azaltılması için, yasal tedbirlerin yanı sıra üniversiteler ile sağlık ve milli eğitim bakanlıkları başta olmak üzere, diğer ilgili kamu kurumları ile sivil toplum kuruluşlarının birlikte hareket ederek ciddi bir kamuoyu oluşturmaları gerekmektedir.

Anahtar Kelimeler: Sigara kullanımı, öğrenci, sağlık, binary lojistik regresyon

\section{Determining Factors Affecting Cigarette Use of Students: The Case of Ondokuz Mayıs University, Samsun, Turkey}

\begin{abstract}
The purpose of this study was to determine the factors affecting cigarette use of the students at Ondokuz Mayis University, Samsun, Turkey. The research data were collected from 384 students who answered the questionnaires. The chisquare test was used to determine the differences between smokers and non-smokers, and the t-test was used to compare group averages. Factors affecting cigarette use of students were determined by binary logistic regression analysis. The results of the research showed that male students used more cigarettes than females. Cigarette use increased after university, especially in the second and third years. The educational level and cigarette use habits of the parents affected students smoking behavior. According to the results of the model the most important factors affecting cigarette use were smoking permission situation in the student resident, smoking status of the mother, gender, and age of the student. In order to reduce cigarette use of students, besides taking legal measures, Ministry of Health, Ministry of National Education, and non-governmental organizations have to collaborate, build mutual prevention programs to raise public awareness.
\end{abstract}

Keywords: Cigarette use, student, health, binary logistic regression 


\section{Giriş}

Sigara, içerdiği nikotin ve diğer zararlı maddelerden dolayı insan sağlığını tehdit eden ve bağımlılık yapan bir maddedir. Sigaranın insanlarda yol açtığ 1 başlıca hastalıklar; kalp ve damar hastalıkları, bronşların daralması sonucu akciğer rahatsızlıkları, damarlarda tıkanma ve buna bağlı felç, midede gastrit, ülser, mide kanseri, ciltte sararma, kırışıklık, cilt kanseri, ağız kokusu, dişlerde sararma, gebelikte erken doğum ve buna bağlı gelişim bozuklukları, doğum sonrası ise sütün kesilmesi olarak karşımıza çıkmaktadır (Anonim, 2018a). Dünya Sağlı Örgütü'nün verilerine göre, dünyadaki en büyük halk sağlığı tehditlerinden biri olan tütün epidemisi, yılda 7 milyondan fazla kişinin ölümüne neden olmaktadır. Bu ölümlerin 6 milyondan fazlası direkt tütün kullanımından kaynaklanırken, yaklaşık 890 bin kişi sigara kullanmadıkları halde pasif içicilikten hayatını kaybetmektedir (Anonymous, 2017).

Sigara kullanımının yaygın olduğu Türkiye'de, 1999 yılında 114.4 milyar adet sigara ile tüketim zirveye ulaşmış, ancak 2009 yılında devreye giren kapalı alanlarda sigara içme yasağının etkisiyle gerileme eğilimine girmiştir. Sigara tüketimi, 2011 y1lı sonunda 91.2 milyar adete düşmüş, bu yıldan sonra tekrar artmaya başlayarak 2017 y1lında 106.22 milyar adete ulaşmıştır (Şekil 1). Türkiye'de 2016 y1lı itibariyle 15 yaşın üzerindeki her dört kişiden biri (\% 26.5) sigara kullanmaktadır (Anonymous, 2017).

Çocukluktan erişkinliğe geçiş dönemi olarak kabul edilen adolesan döneminde (10-19 yaş); fiziksel, psikolojik, sosyal, bilişsel ve cinsel değişimler yaşanmaktadır (Özcebe, 2008). Özellikle lise ve üniversite öğrencileri adolesan döneminde olmaları nedeniyle, sigara kullanmak gibi kötü alışkanlıklar edinmeye daha eğilimlidirler. Ayrıca öğrencilerin içinde bulundukları ortam ve arkadaşlık ilişkileri, sigara kullanımını özendirdiği gibi teşvik edici de olabilmektedir. Nitekim Kara ve ark. (2011) tarafindan yapılan bir araştırmada, sigara kullanımına 21 yaşından önce başlayanların, bağımlı olma olasılığının daha yüksek olduğu belirtilmiştir. Dolayısıyla öğrencilerin sigara kullanımını etkileyen faktörlerin tespit edilerek çözüm önerilerinin geliştirilmesi, bağımlılı̆̆ önleme ve tüketimi azaltmaya yönelik çalışmalara katkı sağlayacaktır.

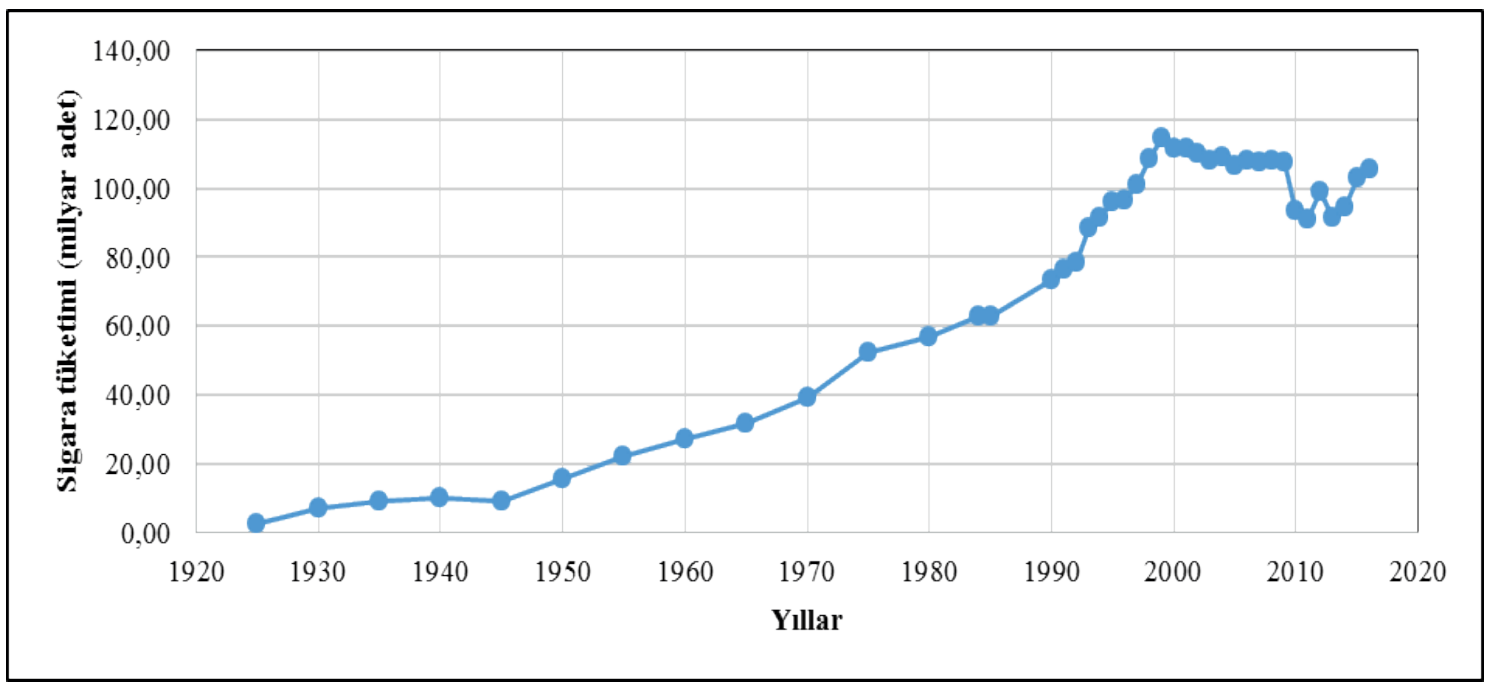

Şekil 1. Türkiye'de yıllara göre sigara tüketimi (Anonim, 2018b)

Öğrencilerin sigara kullanımı konusunda çok sayıda yerli ve yabancı araştırma yapılmıştır (Çelik ve ark., 2000; Mammas ve ark., 2003; Çelik ve ark., 2004; Pekşen ve ark., 2005; Mandil ve ark., 2007; Tanrıkulu ve ark., 2009; Goniewicz ve ark., 2014; Jha ve ark., 2014; King ve ark., 2014; Inderjit ve ark., 2015; Akçalı ve ark., 2016; Onurlubaş ve ark., 2017; Wang ve ark., 2017). Yapılan araştırmalarda, gençlerle ilgili sorunların başında sigara bağımlılığının olduğu ve öğrencilerin sigaraya özenmelerinde okuldaki ortamla birlikte aile ilişkilerinin de büyük rol oynadığı tespit edilmiştir. $\mathrm{Bu}$ araştırmanın amacı, Ondokuz Mayıs Üniversitesi öğrencilerinin sigara kullanım durumları ile bunu etkileyen faktörlerin belirlenmesidir. Araştırma sonuçlarının, öğrencilerin sigara kullanım alışkanlıklarının azaltılmasına yönelik alınacak önlemlere katk1 sağlaması ümit edilmektedir. 


\section{Materyal ve Yöntem}

Araştırmanın materyali, Samsun'da bulunan Ondokuz Mayıs Üniversitesine bağlı fen, sosyal ve sağlık bilimlerinde okuyan lisans öğrencileriyle yapılan anketlerden oluşmaktadır. Anket yapılan öğrenci sayısı, ana kitle oranlarına dayalı kümelendirilmemiş tek aşamalı tesadüfi olasılık örneklemesi yöntemiyle (Eşitlik 1) belirlenmiştir (Collins, 1986).

$$
\begin{aligned}
& n=\left(\frac{z_{\alpha / 2}}{d}\right)^{2} * p * q \\
& n=(1.96 / 0.05)^{2} * 0.5 * 0.5=384
\end{aligned}
$$

Eşitlik 1'de; n örnek hacmini, $Z_{\alpha / 2} \% 95$ güven aralığına karşılık gelen tablo değerini, $\mathrm{p}$ incelenen olayın meydana gelme olasılığını, q incelenen olayın meydana gelmeme olasılı̆̆ını $(q=1-p), d$ ise izin verilen hata payını (\% 5) ifade etmektedir. Anketler, 2017-2018 akademik bahar yarıyılında yapılmıştır. Sigara kullanan ve kullanmayan öğrenciler arasında; cinsiyet, sınıf, ikamet yeri, ikamet ettiği yerde sigara içilmesi, ebeveynlerin eğitimi ve birliktelik durumları açısından farklılığın belirlenmesinde ki-kare testi kullanılmıştır. Her iki gruptaki öğrenci ve ailelerinin aylık ortalama gelirleri $\mathrm{t}$ testi ile karşılaştırılmıştır. Öğrencilerin sigara kullanımını etkileyen faktörlerin belirlenmesi için yapılan binary lojistik regresyon analizinde, bağımlı değişken olarak öğrencilerin sigara kullanma durumları ele alınmıştır. Modele dâhil edilen bağımsız değişkenler ise öğrencilerin yaşı, cinsiyeti, harcayabilecekleri aylık gelir, ikamet ettiği yer ile ikamet ettiği yerde sigara içilmesi, ailenin aylık geliri, anne ve babanın eğitimi ile birliktelikleri ve sigara içme durumlaridır.

\section{Bulgular ve Tartışma}

Araştırma sonuçlarına göre, anket yapılan öğrencilerin ortalama yaşı 21'dir. Öğrencilerin $\%$ 52'si erkek, \% 48'i k1z olup, erkeklerde sigara kullanma oranı ( $\%$ 53.3) k1zlardan ( $\%$ 30.1) yüksektir. Sigara kullanan ve kullanmayan öğrenciler arasında, cinsiyet itibariyle istatistiki olarak anlamlı farklılık vardir. Ailelerinin aylık ortalama geliri sigara kullananlarda $3628 \mathrm{TL}$, sigara kullanmayanlarda 3424 TL olarak tespit edilmiştir. Sigara kullanan öğrencilerin harcayabilecekleri aylık gelir 626 TL iken, bu miktar sigara kullanmayanlarda 507 TL'dir. Sigara kullanımı, sağlığı olumsuz etkilediği gibi maddi anlamda da önemli bir masraf kalemini oluşturmaktadır. Öğrencilerin aylık gelirleri yönünden, sigara kullanan ve kullanmayanlar arasinda istatistiki olarak anlamlı farklılık vardır $(\mathrm{p}<0.05)$.
Ailelerinden uzakta olmanın vermiş olduğu özgürlük hissi nedeniyle, öğrencilerin bağımlılık yapan maddeleri kullanma eğilimleri daha fazladır. Sigara kullanan öğrencilerin \% 46.8'i ikinci, $\%$ 46.3'ü üçüncü sınıfa devam etmektedir.

Ebeveynlerin eğitim düzeyinin, öğrencilerin sigara kullanımında etkili olduğu bir gerçektir. Araştırma sonuçları da sigara kullanan ve kullanmayan öğrenciler arasında, annenin eğitim durumu yönünden anlamlı farklılığın olduğunu göstermektedir. Ayrıca sigara içen ebeveynler, çocuklarının zararlı maddelerle tanışmaları açısından kötü örnek teşkil etmektedir. Sigara kullanan öğrencilerin \% 65.1'inin annelerinin, \% 44.3'ünün ise babalarının sigara içtikleri tespit edilmiştir. Araştırma sonuçları, annenin sigara içmesinin öğrencilerin sigara kullanımı üzerinde etkili olduğunu ortaya koymaktadır. Annenin sigara içmesi bakımından, sigara kullanan ve kullanmayan öğrenciler arasındaki farklılık anlamlı bulunmuştur. Ayrıca her iki grup arasında, öğrencinin ikamet ettiği yerde sigara içilmesi yönünden de anlamlı farklılık vardır (Tablo 1).

Öğrencilerin \% 86's1 ailelerinden uzakta yaşamaktadır. $\mathrm{Bu}$ durum, öğrencilerin davranışlarını olumsuz etkilemekte ve sigara gibi kötü alışkanlıklar edinmesine yol açabilmektedir. Model sonuçlarına göre, öğrencilerin sigara kullanımını etkileyen en önemli faktör öğrencinin ikamet ettiği yerde sigara içilmesidir. İkamet edilen yerde sigara içilmesi, öğrencinin sigara kullanma olasılığını kullanmayanlara göre 9.4 kat artırmaktadır. Öğrenciler küçük yaştan itibaren ebeveynlerini örnek aldıkları için, ebeveynlerin sigara içmeleri çocukların sigaraya başlamasında önemli bir etken olmaktadır. Annenin sigara içmesi, öğrencinin sigara kullanma olasılığını 3.9 kat arttırmaktadır. Konuyla ilgili yapılan birçok araştırmada da benzer sonuçlar elde edilmiştir (Mandil ve ark., 2007; Tanrikulu ve ark., 2009; Kara ve ark., 2011). Sigara kullanımı üzerine önemli etkiye sahip diğer bir faktör cinsiyettir. Erkek öğrencilerde sigara kullanma olasılığının, kız öğrencilere göre 2.2 kat fazla olduğu tespit edilmiştir. Erkeklerde özgürlük hissinin fazla olması ve aile baskısını kızlara göre daha az hissetmelerinin bunda etkili olduğu söylenebilir. Yapılan birçok çalışmada da, erkeklerin sigara kullanma oranının yüksek olduğu vurgulanmış ve cinsiyetin sigara kullanımını etkileyen önemli bir değişken olduğu ortaya konulmuştur (Mandil ve ark., 2007; Tanrikulu ve ark., 2009; Jha ve ark., 2014; Akçalı ve ark., 2016). Sigara kullanımında öğrencinin yaşı da önemli olup, yaşın 1 yıl artması sigara kullanma olasılığını 1.1 kat artırmaktadır. Bu durum, aileden uzak olma, özenti ve merak gibi nedenlerle üniversiteye başladıktan sonra 
Tablo 1. Sigara kullanan ve kullanmayan öğrencilere ait özellikler

\begin{tabular}{|c|c|c|c|c|c|c|}
\hline & \multicolumn{2}{|c|}{$\begin{array}{l}\text { Sigara içen } \\
\text { (160) }\end{array}$} & \multicolumn{2}{|c|}{$\begin{array}{c}\text { Sigara içmeyen } \\
(224)\end{array}$} & \multirow[t]{2}{*}{$\chi^{2}$} & \multirow[t]{2}{*}{$\begin{array}{c}\text { Önem } \\
\text { düzeyi } \\
(P)\end{array}$} \\
\hline & Kişi & $\%$ & Kişi & $\%$ & & \\
\hline \multicolumn{7}{|l|}{ Cinsiyet } \\
\hline Erkek & 104 & 53.3 & 95 & 47.7 & \multirow{2}{*}{19.1} & \multirow{2}{*}{$0.001^{* * *}$} \\
\hline $\mathrm{K} 1 \mathrm{z}$ & 56 & 30.1 & 129 & 69.9 & & \\
\hline \multicolumn{7}{|l|}{ Sinif } \\
\hline Birinci & 29 & 33.0 & 59 & 67.0 & \multirow{4}{*}{4.6} & \multirow{4}{*}{0.209} \\
\hline İkinci & 44 & 46.8 & 50 & 53.2 & & \\
\hline Üçüncü & 38 & 46.3 & 44 & 53.7 & & \\
\hline Dördüncü + & 49 & 40.8 & 71 & 59.2 & & \\
\hline \multicolumn{7}{|l|}{ Babanın eğitimi } \\
\hline İlkokul & 24 & 34.8 & 45 & 65.2 & \multirow{4}{*}{3.5} & \multirow{4}{*}{0.310} \\
\hline Ortaokul & 23 & 36.5 & 40 & 63.5 & & \\
\hline Lise & 43 & 42.2 & 59 & 57.8 & & \\
\hline Üniversite & 70 & 46.7 & 80 & 53.3 & & \\
\hline \multicolumn{7}{|l|}{ Annenin eğitimi } \\
\hline İlkokul & 43 & 33.1 & 87 & 66.9 & \multirow{4}{*}{7.9} & \multirow{4}{*}{$0.047^{* *}$} \\
\hline Ortaokul & 42 & 48.8 & 44 & 51.2 & & \\
\hline Lise & 38 & 40.4 & 56 & 59.6 & & \\
\hline Üniversite & 37 & 50.0 & 37 & 57.0 & & \\
\hline \multicolumn{7}{|c|}{ Anne ve babanın birlikteliği } \\
\hline Birlikteler & 142 & 41.0 & 204 & 59.0 & \multirow{2}{*}{0.5} & \multirow{2}{*}{0.453} \\
\hline Ayrilar & 18 & 47.4 & 20 & 52.6 & & \\
\hline \multicolumn{7}{|c|}{ Babanın sigara içmesi } \\
\hline İçiyor & 74 & 44.3 & 93 & 55.7 & \multirow{2}{*}{0.9} & \multirow{2}{*}{0.356} \\
\hline İçmiyor & 86 & 39.6 & 131 & 60.4 & & \\
\hline \multicolumn{7}{|c|}{ Annenin sigara içmesi } \\
\hline İçiyor & 41 & 65.1 & 22 & 34.9 & \multirow{2}{*}{16.9} & \multirow{2}{*}{$0.001^{* * *}$} \\
\hline İçmiyor & 119 & 37.1 & 202 & 62.9 & & \\
\hline \multicolumn{7}{|c|}{ Öğrencinin ikamet ettiği yer } \\
\hline Yurt & 77 & 34.8 & 144 & 65.2 & \multirow{3}{*}{12.3} & \multirow{3}{*}{$0.002^{* * *}$} \\
\hline Öğrenci evi & 60 & 55.0 & 49 & 45.0 & & \\
\hline Aile yan 1 & 23 & 42.6 & 31 & 57.4 & & \\
\hline Öğrencinin ikam & & & & & & \\
\hline İçiliyor & 13 & 10.6 & 110 & 89.4 & & \\
\hline İçilmiyor & 147 & 56.3 & 114 & 43.7 & 72.0 & 0.001 \\
\hline
\end{tabular}

**: $\% 5$ ve ***: \% 1 düzeyinde istatistiki olarak anlamlıdır

öğrencilerin sigara kullanma eğiliminin arttı̆̆ını göstermektedir. Yapılan birçok araştırmada da, yaşın sigara kullanımını etkileyen önemli bir faktör olduğu tespit edilmiştir (Mandil ve ark., 2007; Tanrıkulu ve ark., 2009; Akçalı ve ark., 2016; Onurlubaş ve ark., 2017). Sigara kullanımını etkileyen diğer bir faktör, aileden gelen para ve alınan burs miktarı ile yarı zamanlı çalışmayla elde edilen gelirden oluşan öğrencinin aylık harcayabileceği gelirdir. Öğrencilerin sigara satın almak için her ay bütçelerinden belli miktarda para ayırmaları gerekmektedir. Araştırmada, ögrencilerin gelirleri ile ailelerinden gelen para miktarındaki artışın sigara kullanımını artırdığ1 tespit edilmiştir (Tablo 2). Kara ve ark. (2011) yaptıkları araştırmada benzer sonuçlara ulaşmış, gelir düzeyi ile sigara içme durumu arasında önemli bir ilişkinin olduğunu ortaya koymuşlardır.

\section{Sonuçlar}

Araştırmada öğrencilerin sigara kullanımını etkileyen önemli faktörler; ikamet edilen yerde sigara içilmesi, annenin sigara içmesi, öğrencinin cinsiyeti ve yaşı olarak tespit edilmiştir. Sigara kullanma oranı, erkek öğrencilerde kızlara oranla daha fazla olup, kullanma oranının özellikle ikinci ve üçüncü sınıflarda arttığı görülmektedir. Öğrencilerin aylık gelirlerinin artması sigara kullanma olasılığını artırmaktadır. Çocukluk döneminde öğrencilere yeteneklerine göre çeşitli hobilerin kazandırılması sayesinde, öğrenciler gelirlerini sigara gibi kötü alışkanlıklar yerine kişisel özelliklerini geliştirmeleri için harcayabilirler.

Bireylerin zararlı madde alışkanlıklarının çoğu çocukluk ve gençlik dönemlerinde geliştiği için, bu 
Tablo 2. Öğrencilerin sigara kullanımını etkileyen faktörler

\begin{tabular}{|c|c|c|c|c|c|c|c|}
\hline \multirow[t]{2}{*}{ Değişken } & \multirow{2}{*}{$\begin{array}{c}\text { Regresyon } \\
\text { katsay1s1 } \\
(\beta)\end{array}$} & \multirow{2}{*}{$\begin{array}{l}\text { Standart } \\
\text { hata }\end{array}$} & \multirow{2}{*}{$\begin{array}{l}\text { Wald } \\
\text { değeri }\end{array}$} & \multirow{2}{*}{$\begin{array}{c}\text { Önem } \\
\text { düzeyi } \\
(P)\end{array}$} & \multirow{2}{*}{$\begin{array}{c}\text { Olabilirlik } \\
\text { oran1 } \\
{[\operatorname{Exp}(\beta)]}\end{array}$} & \multicolumn{2}{|c|}{$\begin{array}{l}\operatorname{EXP}(\beta) \text { için \% } 95 \\
\text { güven aralığ } 1\end{array}$} \\
\hline & & & & & & En düşük & En yüksek \\
\hline Sabit & -5.478 & 1.080 & 25.703 & $<0.001^{* * *}$ & 0.004 & - & - \\
\hline Yaş & 0.106 & 0.047 & 5.149 & $0.023^{* *}$ & 1.112 & 1.015 & 1.219 \\
\hline Cinsiyet (Erkek) & 0.803 & 0.249 & 10.383 & $<0.001^{* * *}$ & 2.232 & 1.370 & 3.636 \\
\hline Aile geliri (TL/ay) & $<0.001$ & $<0.001$ & 3.050 & $0.081^{*}$ & 1.000 & 1.000 & 1.000 \\
\hline $\begin{array}{l}\text { Öğrencinin harcayabileceği } \\
\text { gelir (TL/ay) }\end{array}$ & 0.002 & 0.001 & 7.244 & $0.007^{* * *}$ & 1.002 & 1.000 & 1.003 \\
\hline Anne sigara içiyor & 1.358 & 0.345 & 15.498 & $<0.001^{* * *}$ & 3.890 & 1.978 & 7.650 \\
\hline $\begin{array}{l}\text { Öğrencinin ikamet ettiği yerde } \\
\text { sigara içiliyor }\end{array}$ & 2.236 & 0.340 & 43.178 & $<0.001^{* * *}$ & 9.356 & 4.802 & 18.227 \\
\hline
\end{tabular}

*: \% 10, **: \% 5 ve ***: \% 1 düzeyinde istatistiki olarak anlamlıdır

dönemlerde ebeveynlerin tartışmasız önemli etkisi vardır. Araştırma sonuçları, öğrencilerin sigara kullanmasında ebeveynlerinin de etkili olduğunu göstermektedir. Bundan dolayı aileler, her şeyden önce çocukları için rol model olduklarını unutmamalıdırlar. $\mathrm{Bu}$ amaçla aileler, çocuklarının öğrencilik döneminde hangi ortamlarda bulunduklarına dikkat etmeli ve çocuk gözetimine özen göstermelidirler. Geleceğin ebeveynleri olan bu öğrencilerin, sigarayı bırakmalarını sağlayacak tedbirlerin alınmasının önemi büyüktür. Aileleriyle birlikte yaşayan öğrenciler daha az sigara kullanmakta, sigara kullanan öğrencilerin büyük bir kısmı ise yurt ya da öğrenci evlerinde kalmaktadır. Ailelerinden uzakta yaşayan öğrenciler, ailenin koruyuculuk etkisinde olmadıkları için daha fazla sigaraya başlama eğilimi göstermektedirler. $\mathrm{Bu}$ amaçla ailelerin çocuklarına her koşulda yanlarında olduklarını hissettirmeleri, maddi olanak sağlamanın yanında manevi desteklerini de devam ettirmeleri gerekmektedir.

Günümüzde sigara kullanımının, doğrudan ya da dolaylı olarak çok sayıda hastalığa neden olduğu kanıtlanmıştır. Sigara sadece kişilerin sağlığını değil, aile ekonomisini ve sosyal ilişkilerini de bozmaktadır. $\mathrm{Bu}$ nedenle küçük yaşta sigaraya başlamanın önüne geçilmesi, sigarayı özendirecek her türlü uygulamaların yasaklanması ve bunun için kamu kurumları ile sivil toplum kuruluşlarının birlikte hareket etmesi büyük önem taşımaktadır. Son yıllarda sigara kullanımını azaltmaya yönelik çok sayıda çalışma yapılmış ve çeşitli tedbirler alınmıştır. Ancak yasal düzenlemeler, yoğun propaganda ve bilinçlendirme çalışmalarına rağmen, sigaranın özellikle gençler arasında yaygınlaşmasının önüne geçilememiştir. Dolayisıyla toplumun genelinde sigara kullanımının önlenmesine yönelik yasaların yeniden düzenlenmesi, sigarayı birakmak isteyenlere daha fazla destek olunması, pasif içiciliğin önlenmesi ve sigaraya bağlı hastalıklar hakkında toplumun bilgilendirilmesine yönelik çalışmaların artırılması başlıca tedbirler olarak ele alınmalıdır.

\section{Kaynaklar}

Akçalı, N., Nazlıcan, E., Akbaba, M., Okyay, R.A., 2016. Smoking prevalence, behavior, and associated factors in vocational school of health services Students. Turkish Journal of Occupational /Environmental Medicine and Safety, 1(4): 23-33.

Anonim, 2018a. Yeşilay. (https://www.yesilay.org.tr/tr/ bagimlilik/sigara-ve-tutun-bagimliligi), (Erişim tarihi: 03.05.2018).

Anonim, 2018b. Tütün Mamulleri Piyasas1 Düzenlemeleri. T.C. Tarım ve Orman Bakanlığı, Tütün ve Alkol Dairesi Başkanlığı, (http:// www.tapdk.gov.tr/tr/piyasa-duzenlemeleri/ tutunmamulleri-piyasasi/tutun-mamulleri-istatistikleri. aspx), (Erişim tarihi: 27.09.2018).

Anonymous, 2017. Tobacco. World Health Organization (WHO), (http://www.who.int/mediacentre/factsheets /fs339/en/), (Erişim tarihi: 10.03.2018).

Collins, M., 1986. Sampling (Eds: R. Worcester et al., 1986), Consumer Market Research Handbook.

Çelik, H.C., Satıcı, Ö., Çelik, M.Y., 2004. Kronik sigara içme alışkanlığı olan üniversite öğrencilerinin tutumlarına ilişkin değişkenlerin aşamalı kümeleme yöntemi çözümlemesi. İnönü Üniversitesi Tip Fakültesi Dergisi, 11(4): 217-222.

Çelik, P., Esen, A., Yorgancıŏlu, A., Şen, F.S., Topçu, F., 2000. Manisa ilinde lise öğrencilerinin sigaraya karşı tutumları. Toraks Dergisi, 1(1): 61-66.

Goniewicz, M.L., Gawron, M., Nadolska, J., Balwicki, L., Sobczak, A., 2014. Rise in electronic cigarette use among adolescents in Poland. Journal of Adolescent Health, 55(5): 713-715.

Inderjit, M.G., Karibasappa, G.N., Nagesh, L., 2015. Tobacco and alcohol use among male dental and medical students studying in Davangere city: A crosssectional survey. Journal of Dental Research and Review, 2(4): 156-160.

Jha, S.K., Agrawal, R., Dhakal, P.K., Nepal, M., Jayan, A., Gautam, N., 2014. Smoking and alcohol intake among students in medical college of South Western 
Region, Nepal. Journal of Universal College of Medical Sciences, 2(4): 19-23.

Kara, S., Baş, F.Y., Açıkalın, C., 2011. Sigara içme davranışları ve etkili faktörler: Tıp ve Diş Hekimliği Fakültelerinin ilk ve son sınıf öğrencileri üzerinde çalışma. Smyrna Tip Dergisi, 1(1): 16-21.

King, B.A., Tynan, M.A., Dube, S.R., Arrazola, R., 2014. Flavored-little-cigar and flavored-cigarette use among US middle and high school students. Journal of Adolescent Health, 54(1): 40-46.

Mammas, I.N., Bertsias, G.K., Linardakis, M., Tzanakis, N.E., Labadarios, D.N., Kafatos, A.G., 2003. Cigarette smoking, alcohol consumption, and serum lipid profile among medical students in Greece. The European Journal of Public Health, 13(3): 278-282.

Mandil, A., Hussein, A., Omer, H., Turki, G., Gaber, I., 2007. Characteristics and risk factors of tobacco consumption among University of Sharjah students, 2005. Eastern Mediterranean Health Journal, 13(6): $1449-1458$
Onurlubaş, E., Yıldız, E., Yıldız, S., 2017. Üniversite öğrencilerinin sigara tüketimini etkileyen faktörler: Trakya Üniversitesi öğrencileri üzerine bir uygulama. The Journal of International Scientific Researches, 2(4): 83-92.

Özcebe, H., 2008. Gençler ve Sigara. Sağlık Bakanlığı, Yayin No: 731.

Pekşen, Y., Canbaz, S., Sünter, A.T., Tunçel, E.K., 2005. Ondokuz Mayıs Üniversitesi Yaşar Doğu Beden Eğitimi ve Spor Yüksek Okulu öğrencilerinde sigara içme sıklığ1 ve etkileyen faktörler. Journal of Dependence, 6(3): 111-116.

Tanrıkulu, A.C., Çarman, K.B., Palancı, Y., Çetin, D. Karaca, M., 2009. Kars il merkezinde çeşitli üniversite öğrencileri arasında sigara kullanım sıklığ ve risk faktörleri. Tur Toraks Dergisi, 11: 101-106.

Wang, M., Wang, H., Fei, F.R., Xu, C.X., Du, X.F., Zhong, J.M., 2017. The associations between cigarette smoking and health-related behaviors among Chinese school-aged adolescents. Tobacco Induced Diseases, 15(27): 1-7. 